\title{
The Effects of Type and Quantity of Input on Iranian EFL Learners' Oral Language Proficiency
}

\author{
Zahra Hassanzadeh (Corresponding author) \\ Azad University of Ardabil, Iran \\ E-mail: hassanzadehzahra63@yahoo.com \\ F. Vahdany \\ Azad University of Ardabil, Iran
}

Received: 15-12-2013

doi:10.7575/aiac.ijalel.v.3n.3p.124
Accepted: 05-02-2014

Published: 01-05-2014

URL: http://dx.doi.org/10.7575/aiac.ijalel.v.3n.3p.124

\begin{abstract}
In the written texts on foreign language learning, a group of studies has stressed the function of learning context and learning chances for learners' language input. The present thesis had two main goals: on the one hand, different types of input to which Iranian grade four high school EFL learners' are exposed were looked at; on the other hand, the possible relationship between types and quantity of input and Iranian EFL learners' oral proficiency was investigated. It was supposed that EFL learners who have access to more input will show better oral proficiency than those who do not have. Instruments used in the present study for the purpose of data collation included PET test, researcher- made questionnaire, oral language proficiency test and face- to -face interview. Data were gathered from 50 Iranian female grade four high school foreign language learners who were selected from among 120 students whose score on PET test were $\pm 1 \mathrm{SD}$ from the mean score. The results of the Spearman rank -order correlation test for the types of input and oral language proficiency scores, showed that the participants' oral proficiency score significantly correlated with the intended four sources of input including spoken ( $\mathrm{rho}=0.416$, sig $=0.003$ ), written $(\mathrm{rho}=0.364$, sig $=0.009$ ), aural (rho= 0.343 , sig $=0.015$ ) and visual or audio-visual types of input ( $\mathrm{rho}=0.47$, sig $=0.00)$. The findings of Spearman rank -order correlation test for the quantity of input and oral language proficiency scores also showed a significant relationship between quantity of input and oral language proficiency $(\mathrm{rho}=0.543$, sig $=0.00)$. The findings showed that EFL learners' oral proficiency is significantly correlated with efficient and effective input. The findings may also suggest answers to the question why most Iranian English learners fail to speak English fluently, which might be due to lack of effective input. This may emphasize the importance of the types and quantity of input in EFL classes and syllabus designers.
\end{abstract}

Keywords: type of Input, quantity of input, Oral language proficiency

\section{Introduction}

According to Swain (1985), all types of data from a target language that the learners are introduced to and from which they learn are called "input". So far, foreign and second language research has paid particular attention to input comprehension. These researches had been under the influence of the hypotheses that consider a relationship between the comprehension of the input and its effectiveness to the acquisition process. Ellis (1995) suggests that an important aspect of educating foreign language learners is the use of understandable input, or specialized instructional techniques and methodology that make content intelligible to students at all English proficiency levels. In connection with input of EFL learners, many studies have enquired into whether measures of input might have an effect on their performance on oral proficiency tests. While some researchers (Seliger, 1977; Spada, 1986) have concluded that EFL learners with a significant degree of informal exposure are more proficient than those with less, others have found the opposite views (Day, 1985; Krashen \& Seliger, 1976). The present research scrutinized what types and quantities of input Iranian grade four high school EFL learners are exposed to and how these inputs affect their oral language proficiency.

Different research studies have been done comparing the amount of language competence and the amount of exposure to the language in classroom-years or the age of the language acquirer, and the acculturation of the language acquirer. The results of these studies are in agreement with acquisition hypotheses: the more accessible input one receives in lowanxiety situations, the more language competence that one will have (Ellis, 2002). In this study, it was hypothesized that students who have more input will show more oral proficiency improvement than those who do not have. Therefore, teachers need to create a convenient classroom conditions to supply different types and amounts of input for EFL learners.

\section{Research questions}

The specific research questions addressed in this study are:

Q1. What are different types of input to which Iranian grade four high school EFL learners' are exposed?

Q2. Is there any relationship between types of input and Iranian EFL learners' oral proficiency?

Q3. Is there any relationship between quantity of input and Iranian EFL learners' oral proficiency? 


\section{Method}

\subsection{The Design of the Study:}

This study adopted ex post facto design. Four methods of data collection were used to obtain data: questionnaire, PET test, oral proficiency test, and semi- structured interview.

\subsection{Participants}

The subjects participating in this study were 50 Iranian female grade four high school foreign language learners to answer the questionnaire items. The participants differed in age from 17 and 19 years old. They were selected from among 120 students whose score on PET test were $\_1 \mathrm{SD}$ from the mean score. Out of the 50 students, 15 of them took part in a face to face interview.

Table 1. Sample Population

\begin{tabular}{lccc}
\hline gender & Number of participants & Age & Type of Program \\
\hline female & 120 students & $17-19$ & PET test administration \\
\hline female & 50 students & $17-19$ & Oral proficiency test \\
\hline female & 20 students & $17-19$ & Pilot study of the questionnaire \\
\hline female & 2 EFL teachers & 33 and 41 & Scoring the participants' oral production \\
\hline female & 50 students & $17-19$ & Questionnaire administration \\
\hline female & 15 students & $17-19$ & Face- to -face interview \\
\hline
\end{tabular}

\subsection{Instruments and Materials}

1. Measure of L2 Proficiency (PET test): To ensure the subjects were roughly at the same level of language proficiency, the standardized English proficiency test (Preliminary English Test) was administered to 120 students. The participants took the structure, vocabulary and reading comprehension sections of the test with a maximum possible score of 100 points. Fifty students whose scores fell \pm SD from the mean score were selected as the main sample for the present study.

2. Oral Language Proficiency Test: In order to evaluate the subjects' oral proficiency, all of the 50 participants took an oral test by saying something which was related to their lives regardless of their personal details, that is, age, family background, school where they studied and time they spent in learning English. As they had learned the past tense at school, the topic "What happened to you yesterday?" was chosen. The task was carried one by one in a quiet room in the form of face-to-face interactions with the researcher. They were only encouraged to think aloud about what they had done on the previous day by saying "first, then, after that..." In assessing each learner's oral performance, the researcher used the following criteria that were adapted from those specified in $\mathrm{Li}$ (2003). The oral production of the participants was scored by two different scorers who were experienced foreign language teachers. The total score for each participant on the oral production test was the mean of the two raters' scores. The consistency of the two raters' judgments was tested using correlation analysis that showed a relatively high level of inter-rater reliability for oral production scores. The obtained reliability index was $(r=0.87)$ for the two raters.

3. Questionnaire: The main research tool in this study was a researcher-made questionnaire that was given to the selected sample. The questions were grouped into four categories, including aural input, written input, spoken input, and input from other sources. To check the reliability of the questionnaire, it was piloted on a different sample that consisted of 20 subjects. Cronbach's alpha statistic was computed for the 31 questionnaire items and a reliability of .83 was obtained which is considerably higher than the minimum required value of 0.70 .

4. Face-To- Face Interview: The interview questions were based on a questionnaire that included the amount and frequency that the participants spoke in the target language or had access to L2 sources, the types of language activities they did, who they spoke with, and how they prepared for the test. The questions were grouped into the following ten questions:

\section{Interview Questions:}

1. How do you prepare yourself for language class?

2. Which type of dictionaries do you use while reading a passage in English?

3. Do you often watch English TV programs?

4. Do you often read English books?

5. Do you often speak English in daily life?

6. Whom do you usually speak English to?

7. Which types of language activities do you do to improve your English?

8. Do you have any native English speakers teach you English?

9. Have you ever lived in English speaking countries?

10. Do you often communicate with native speakers of English on the net? 


\subsection{Data Collection Procedure}

A total number of 50 females of fourth grade in high schools learning English as a foreign language in four classes were chosen based on their score on PET test. The main data was accumulated through a descriptive study and a questionnaire. The procedure of the study included the administration of the instruments and statistical analysis. For sample selection the PET test (Preliminary English Language Test) was administered and a total number of 50 students were selected from among those who scored \pm 1 SD from the mean score. Then they were involved in an oral proficiency test to determine their level of oral production. The researcher directed the questionnaire in April 2012. Before administering the questionnaire to the main sample, a pilot study was conducted to examine whether any questions were problematic in the questionnaire. The face validity of the questionnaire was also analyzed by the thesis advisor. In the main study, the Farsi translation of the questionnaire was distributed to the selected students at their classes. The researcher supplied some instructions and needed guidance before responding.

\section{Results}

\subsection{Oral Language Proficiency Test}

In order to evaluate the subjects' oral proficiency, all of the 50 participants took part in an oral test by saying something which was connected to their lives irrespective of their confidential details, that is, age, family background, school where they studied and time they devoted for learning English. The task was conducted one by one in a silent room in the form of face-to-face interactions with the researcher. In evaluating each learner's oral performance, the researcher used measures that were adopted from those specified in the RSA Test battery. The oral production of the participants was scored (based on the criteria suggested by the researcher) by two different scorers who were experienced foreign language teachers. The consistency of the two raters' judgments was tested using correlation analysis that showed a relatively high level of inter-rater reliability for oral production scores. The estimated reliability index was $(r=0.87)$ for the two raters. The total score for each participant on the oral production test was the mean of the two raters' scores. Descriptive statistics was run to the results of the participants' total oral proficiency test scores the results of which are presented in table 2 .

Table 2. Statistics for the Oral Proficiency Score

\begin{tabular}{llc}
\hline $\mathrm{N}$ & $\begin{array}{c}\text { Valid } \\
\text { Missing }\end{array}$ & 50 \\
Mean & 0 \\
\hline Median & 14.47 \\
\hline Mode & 14.75 \\
\hline Std. Deviation & 15.00 \\
\hline Minimum & 2.11 \\
\hline Maximum & 10.50 \\
\hline Sum & 18.50 \\
\hline
\end{tabular}

\subsection{Research Question One: What are different types of input to which Iranian grade four high school EFL learners' are exposed?}

The examination of each questionnaire item for the type and quantity of input that Iranian EFL learners were exposed to depicted that there seemed to be four equitably separate types of input. They could be grouped into written, aural, spoken, and other sources of information such as visual or audio- visual input. The summary statistics for the individual items of the questionnaire revealed interesting information about the respondents' types and quantity of foreign language input. The low mean rank of spoken input indicated that Iranian EFL learners have little access to foreign language spoken input. This type of input had the lowest level for foreign language learners; on the other hand, the high mean rank of aural input showed that their foreign language learning was more affected and built up through listening input that they receive inside or outside the language learning situation. This means that the participants get the majority of language input through listening to English on CD, or radio, listening English songs, teachers' speaking English in the classroom, and listening to the audio sections of their textbook. Therefore, aural input seems to be the main source of input for the participants in the study.

Although speaking is essential for conveying ideas in any language (Wong Fillmore, 1983), unfortunately Iranian EFL learners have limited opportunity to express their ideas and practice language through speaking. However, concerning other sources of input such as writing SMS in English, letter writing, diary writing or the amount of audio- visual input such as watching films or video clips, they reported varied amounts of input. The following table summarizes different types of input that Iranian EFL learners are exposed to and thus answers the first research question. 
Table 3.Types of Input That Iranian EFL Learners Are Exposed To

\begin{tabular}{l|l}
\hline Type of input & Total mean rank \\
\hline Spoken input & 0.69 \\
\hline Written input & 1.05 \\
\hline Visual or audio visual input & 1.21 \\
\hline Aural input & 1.33
\end{tabular}

4.3 Research Question Two: Is there any relationship between types of input and Iranian EFL learners' oral proficiency?

Table 4. Summary Statistics for Different Types of Input

\begin{tabular}{lccccc}
\hline & $\begin{array}{c}\text { Written } \\
\text { input }\end{array}$ & $\begin{array}{c}\text { Aural } \\
\text { input }\end{array}$ & Spoken input & $\begin{array}{c}\text { Other sources of } \\
\text { input }\end{array}$ \\
\hline $\mathrm{N}$ & Valid & 50 & 50 & 50 & 50 \\
& Missing & 0 & 0 & 0 & 0 \\
\hline Mean & 1.05 & 1.34 & .69 & 1.21 \\
\hline Std. Deviation & .43 & .38 & .33 & .47 \\
\hline Minimum & .40 & .50 & .07 & .28 \\
\hline Maximum & 2.40 & 2.66 & 1.62 & 2.57 \\
\hline
\end{tabular}

The four types of input recognized in the learners' responses to the questionnaire were submitted to Spearman rank order correlation to examine whether there is a statistically significant relationship between the total ranks of the types of input and EFL learners' oral proficiency. By running the Spearman rank- order correlation test it was found that there is a significant relationship between them. (See Table 5)

The relationship between types of input and EFL learners' oral proficiency gains as determined by Spearman rank order correlation test, revealed that the participants' oral proficiency score significantly correlated with the determined four sources of input. The spoken input $(\mathrm{rho}=0.416$, sig $=0.003$ ), written input ( $\mathrm{rho}=0.364$, sig $=0.009$ ), aural input $(\mathrm{rho}=0.343, \mathrm{sig}=0.015)$ and visual or audio-visual types of input was $(\mathrm{rho}=0.47, \mathrm{sig}=0.00)$. Thus, the answer to the second research question is provided and the first null hypothesis is rejected suggesting that there is statistically a positive and meaningful relationship between types of input and Iranian EFL learners' oral proficiency score $(p \leq 0.05)$.

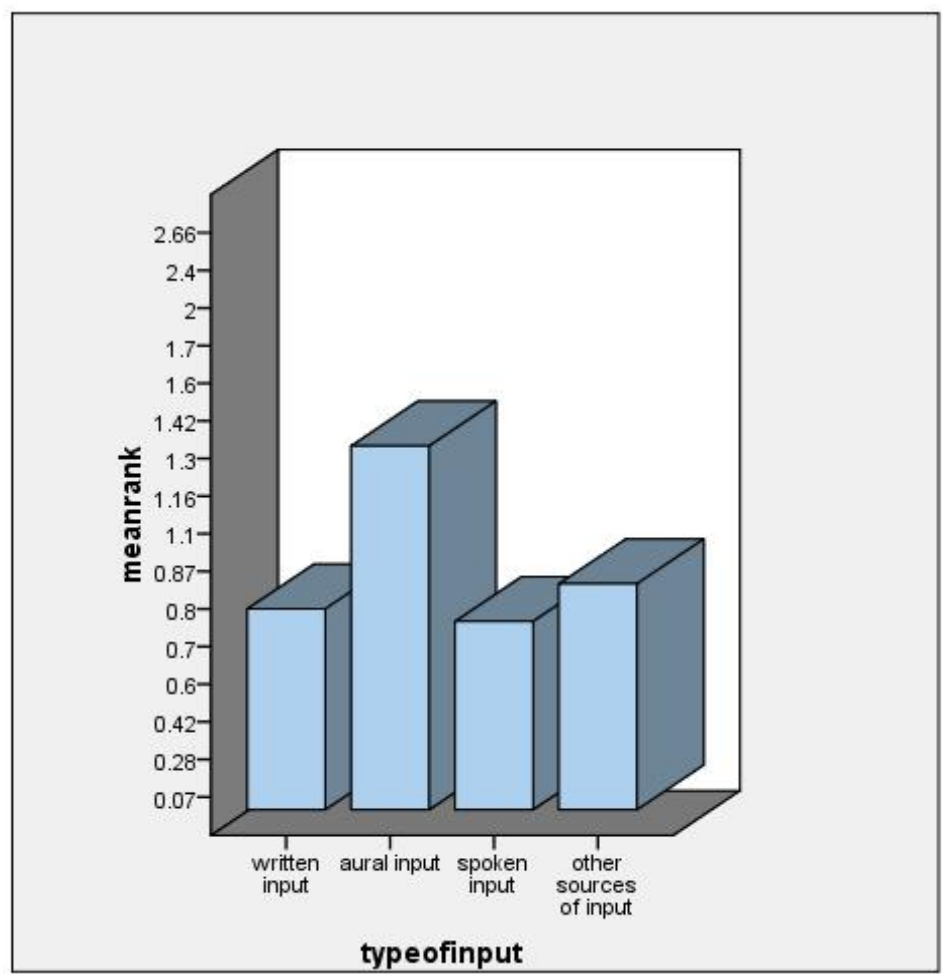

Bars show Mode

Figure1. The mean rank for different types of input 
Spearman's rho other sources of input

\begin{tabular}{ccc} 
& Sig. (2-tailed) & .000 \\
& $\mathrm{~N}$ & $.416^{* *}$ \\
\hline Spoken input & Correlation Coefficient & .003 \\
& Sig. (2-tailed) & 50 \\
\hline Aural input & $\mathrm{N}$ & $.343^{* *}$ \\
& Correlation Coefficient & .015 \\
& Sig. (2-tailed) & 50 \\
\hline Written input & $\mathrm{N}$ & $.364^{* *}$ \\
& Correlation Coefficient & .009 \\
& Sig. (2-tailed) & 50
\end{tabular}

\section{Oral proficiency score} $.475^{* *}$$$
475
$$

Table 5 reveals the relationship between each type of input and EFL learners' oral proficiency. The summary illustrated statistically significant relationship between all pairs. It can be concluded that there is a positive relationship between written, aural, spoken, and other sources of input (visual or audio- visual input) and EFL learners' oral proficiency.

4.4 Research Question Three: Is there any relationship between quantity of input and Iranian EFL learners' oral proficiency?

Table 6. Correlations between Oral Proficiency Gains and Quantity of Input

\begin{tabular}{llll}
\hline & & $\begin{array}{l}\text { Oral proficiency } \\
\text { score }\end{array}$ \\
\hline Spearman's rho & Total mean rank & Correlation Coefficient & $.543^{* *}$ \\
& & Sig. (2-tailed) & .000 \\
& $\mathrm{~N}$ & 50 \\
\hline$* *$ Correlation is significant at the 0.01 level (2-tailed).
\end{tabular}

In order to investigate the possible relationship between the participants' oral proficiency with the amount of input they receive in instructional and non- instructional situations, and to examine the second null hypothesis, first the items of the questionnaire were quantified by giving values of 0 to 3 to the four point scale items. Then the points for all items were added up and the result was the subjects' quantity of input in EFL learning situation. Another Spearman rankorder was run to the results of the oral proficiency test and the questionnaire. The findings imply a significant relationship between these two variables $(\mathrm{rho}=0.543$, sig $=0.00)$.

As it is shown in Table 6 , the $\mathrm{p} \leq 0.05$ indicating a relatively high correlation between EFL learners' oral proficiency score and the amount of input they receive in language learning. This suggests that the higher the quantity of input that EFL learner receive, the higher the oral proficiency score will be. Therefore, the second null hypothesis is rejected, too. Thus, there is a positive and statistically significant relationship between EFL learners' quantity of input and their oral language proficiency gains.

\subsection{Face- To Face Interview}

In order to look into other sources of foreign language learning input in instructional and non-instructional settings for each participant, the interviews were directed with 15 participants one week after questionnaire administration. The participants were interviewed in Persian. Each interview took about 30 minutes. It was tape recorded and notes were also taken. The interview questions were based on a questionnaire that included the amount and frequency that the participants spoke in the target language or had access to L2 sources, the types of language activities they did, who they spoke with, and how they prepared for the English class. Like the majority of other Iranian EFL learners in stateschools, nearly half of the participants of the interview had started to learn English from grade one guidance school at the age of 11 and had two English classes each week at guidance school and then one or two classes at high school with Iranian English teachers teaching. There was more than average of 35 students in their class. They complained that the teacher who explained the texts either in English or in Persian rigidly controlled the class. They reported that there was not much interaction between them and their teachers and peers themselves in their language classes. Most of the participants did not have much chance to practice speaking at school. Like the majority of other Iranian EFL learners, they reported that after school, they had to work assignment that occupied all of their free time. 


\section{Discussion and Conclusion}

Foreign language literary texts show that intelligible input plays a crucial role in L2 acquisition (Fradd \& McGee, 1994). The present study suggested that it was possible for Iranian EFL speakers to hold near native-like oral language proficiency in a foreign language setting if they had access to adequate and effective input. This is quite in agreement with the theories of Krashen's exposure to input. Oral language proficiency is one of the main purposes of learning foreign languages that can be improved by appropriate and sufficient input. In Iranian EFL teaching situation, it is a feature that requires exceptional consideration and guidance In order to provide successful teaching; it is inevitable for EFL teachers to evaluate the factors, conditions, and components that underlie speaking success. Effective instruction originated from the careful analysis of this area, as well as sufficient language input and speech enhancement activities will slowly help learners speak English fluently and appropriately.

\section{References}

Day, R. (1985). The use of the target language in context and second language proficiency. In S. Gass \& C. Madden (Eds.), Input in second language acquisition, pp. 257-271. Rowley, MA: Newbury House.

Ellis, R. (1995). Modified Oral Input and the Acquisition of Word Meanings. Applied Linguistics 16: 409-441.

Ellis, R. (2002). Task-based language learning and teaching. Oxford: Oxford University Press.

Fradd, S., \& McGee. P. (1994). Instructional assessment: An integrative approach to evaluating student performance. Reading, MA: Addison-Wesley.

Krashen, S. \& Seliger, H. (1976). The role of formal and informal environments in second language learning. Oxford: Pergamum Press.

Seliger, H. (1977). Does practice make perfect? A study of interaction patterns and L2 competence. Language Learning, 27, 263-278.

Spada, N. (1986). The interaction between types of contact and types of instruction: Some effects on the second language proficiency or adult learners. Studies in Second Language Acquisition, 8, 181-199.

Swain, M. (1985). Communicative competence: Some roles of comprehensible input and comprehensible output in its development. In S. Gass \& C. Madden (Eds.), Input in second language acquisition (pp. 235-256). Cambridge, MA: Newbury House Publishers.

Wong Fillmore, C. J. (1983). On fluency: individual differences in language ability \& language behavior. Academic Press, Inc. 